\title{
KLIPPEL TRENAUNAY SYNDROME: REPORT OF A RARE, MILD FORM OF SYNDROME
}

Shubhangi. V. Agale, Bhavana. M. Bharambe, Ravikiransingh Pawar, A. G. Valand

1. Associate Professor, Department of Pathology, Grant Medical College \& Sir J. J. Group of Hospitals, Mumbai.

2. Assistant Professor, Department of Pathology, Grant Medical College \& Sir J. J. Group of Hospitals, Mumbai.

3. Resident, M. D. Department of Pathology, Grant Medical College \& Sir J. J. Group of Hospitals, Mumbai.

4. Professor \& Head, Department of Pathology, Grant Medical College \& Sir J. J. Group of Hospitals, Mumbai

\section{CORRESPONDING AUTHOR}

Dr. Shubhangi V Agale

Associate Professor, Department of Pathology

Grant Medical College \& Sir JJ Group of Hospitals, Byculla,

Mumbai- 400008.

E-mail: shubhagale@hotmail.com,

Ph: 00919987533498.

ABSTRACT: Klippel Trenaunay Syndrome (KTS) is a congenital vascular disease characterized by malformations of capillary, venous and lymphatic vessels with bony and soft tissue hypertrophy. KTS is a sporadic disease with unknown etiology, and there is no predilection for gender or any particular ethnicity. The disease appears more frequently at birth, childhood or adolescence. It generally affects only one extremity and lesions are present at birth or appear by the age of 12 years. Clinical presentation of this syndrome is protean ranging from minimal asymptomatic disease to life threatening bleeding and embolism. Management of this syndrome includes careful diagnosis, prevention and treatment of complications. We report a case of KTS in a 25 year old female who presented with mild form of disease.

KEYWORDS: Soft tissue hypertrophy, vascular malformation, congenital disease.

INTRODUCTION: Klippel Trenaunay is a rare, congenital disorder characterized by a triad of capillary vascular malformation, venous malformation and soft tissue or bone hypertrophy.[1-7] It usually affects lower extremity ${ }^{[6]}$ and lesions are present since birth in approximately $90 \%$ of patients presenting before 12 years of age.[6,8] KTS has a wide spectrum of presentation, from truncular to extratruncular, from infiltrating to limited forms, containing primarily three anomalous vascular elements: veins, capillaries and lymphatics. ${ }^{[7]}$ However patients present with protean manifestations. ${ }^{[2]}$ We report a case of KTS in a 25 year old female who presented with mild form of disease.

CASE REPORT: A 25 year old married female presented to dermatology department of our hospital with multiple red colored lesions on the left lower extremity since birth which were increasing in size with age. She developed difficulty in walking at the age of 6 years. There was no history of similar symptoms in other family members. On examination, she had multiple, erythematous, hyper pigmented plaques on lateral side of left lower extremity with largest plaque of 10x8 cm (Figure 1a).The patient also difficulty in extension of the limb with presence of hypertrophy and varicose veins (Figure 1b). Hematological investigations showed: Hemoglobin of $10.2 \mathrm{gm} \%$, WBC of $10,000 / \mathrm{mm}^{3}$, Platelets of $2,10,000 / \mathrm{mm}^{3}$ and microcytic hypochromic anemia on peripheral smear examination. The vascular anomalies of internal organs were ruled out using abdominal ultrasonography, Doppler studies and CT scan of 
abdomen and pelvic region. The histopathological examination of the skin biopsy showed ectatic blood vessels in upper dermis with stasis of erythrocytes (Figure 2). The histopathological diagnosis of nevus flammeus was offered and considering the clinical features, the case was diagnosed as Klippel Trenaunay Syndrome (mild form).

DISCUSSION: Klippel-Trenaunay Syndrome was first described by two French doctors, Klippel and Trenaunay in 1900.[6,7] The incidence and genetic predisposition has not been proved despite various case reports in world literature.[7] KTS occurs sporadically, and shows no particular racial, sexual or geographical predilection. It affects skin, veins, lymphatic system, bone and soft tissues of an extremity. Clinical presentation of patients with KTS has a wide spectrum from incomplete, mild form of port wine stains and few varicose veins causing only cosmetic deformity to severe disability associated with massive limb overgrowths, chronic pain syndrome, skin infections, arthritis, thrombo- embolism and life-threatening pelvic or recurrent rectal bleeding from venous malformations.[7] Capillary malformation is usually a port wine stain or nevus flammeus. The port-wine stain is usually red to purple in color and is flat. It usually has an irregular margin and clear, sharp border but rarely crosses the midline. It may or may not blanch on pressure. It usually occurs on the ipsilateral side as the affected limb.[9] Varicosities are extensive, atypically very large, take an erratic course and begin to manifest in early childhood.[9] Varicose veins is the characteristic feature affecting the lower limbs which was present in our patient. ${ }^{[2]}$ Deep vein anomalies like venous hypoplasia to frank aneurysm, valve hypoplasia to avalvulia have been described with lymphatic malformations. ${ }^{[7]}$ The bony abnormalities may affect all bones in an extremity or limited to one or two bones. Single limb involvement is found in $80-85 \%$ patients. Apart from hypertrophy or sometimes hypotrophy of bones other deformities includes macrodactyly, syndactyly, split hand deformity, phalangeal agenesis and dislocation of hip joint. ${ }^{[7]}$ At least two of three main symptoms (port-wine stains, varicosity, and hypertrophy of soft tissues and bones) must be present for the diagnosis KlippelTrenaunay syndrome to be accepted. ${ }^{[2]}$ Association with arteriovenous malformation is called as Klippel Trenaunay Weber syndrome. ${ }^{[6]}$ Various authors have described other systemic involvements in patients of KTS. Central nervous system abnormalities may include microcephaly, macrocephaly, cerebral arteriovenous malformations and orbito- frontal varices.[10] Patients may present with neurological symptoms due to compression of spinal cord by hemangiomas. Gastrointestinal bleeding and genitourinary lesions like hematuria and vascular malformations of scrotum, penis, vulva, vagina and bladder may also occur.[10]

Several theories have been proposed which include (1) Servelle's theory of a primary obstruction of the venous system resulting in venous hypertension and therefore development of abnormal venous pathways and tissue overgrowth; (2) failure of regression of the lateral limb bud vein; and (3) alteration of the tight balance between angiogenesis and vasculogenesis, which is controlled by numerous genes, among other theories.[7] Most recent being mutation in angiogenic factor VG5Q leading to vascular abnormalities.[3]

The management of KTS has been largely conservative with compression therapy as mainstay of treatment..7] Conservative measures for varicose veins like compression stockings, alleviating pain by painkillers, antibiotics for infections, anticoagulant therapy for thrombophlebitis, laser for ulcers and port wine stains is indicated. Surgery is indicated for cosmetic reasons or for complications of venous insufficiency and for bone or soft tissue overgrowth. The conservative management is sufficient in mild form of KTS but in female patients of reproductive age group, KTS increases obstetric risk and can exacerbate 
complications mainly thromboembolism and hemorrhagic. Probably risk is 10 times higher than in the normal population. ${ }^{[1,2]}$ The other factors which exacerbate this risk are oral contraceptives, surgery and pregnancy. $[1,2,4,11]$

So these patients have to be managed with multidisciplinary approach and must be counseled for: a) Use of contraceptive measures other than oral contraceptive pills b) Pregnancy related complications such as deep vein thrombosis, thromboembolism, and coagulopathy c) Surgery for cosmetic appearance of the leg and d) Risk of abnormalities in the fetus.

The multidisciplinary management with long term, regular follow up is mandatory in female patients with Klippel-Trenaunay Syndrome.

CONCLUSIONS: Klippel Trenaunay syndrome is a rare condition with protean manifestations which should be extensively investigated for the reason of being associated with various systemic manifestations and these patients have to be managed accordingly. The clinicians need to be aware of mild form of KTS which can be managed conservatively and has better prognosis. KTS occurring in female patients of reproductive age group has different implications and has to be managed by a multidisciplinary team of obstetrician, physician and surgeon.

\section{REFERENCES:}

1. González-Mesa E, Blasco M, Andérica J, Herrera J. Klippel-Trenaunay syndrome complicating pregnancy. BMJ Case Rep doi: 10.1136/bcr-2012-006534.

2. Gundogan TG, Jacquemyn Y. Klippel - Trenaunay syndrome and pregnancy. Obstetr \& Gynaecol Int doi: 10, 1155/ogt-2010706850.

3. Tian XL, Kadaba R, You SA, Liu M, Timur AA, and Yang L, et al.: Identification of an angiogenic factor that when mutated causes susceptibility to Klippel-Trenaunay syndrome. Nature. 2004; 427:640-5.

4. Martin JR, Pels SG, Paidas M, Seli E. Assisted reproduction in a patient with KlippelTrenaunay syndrome: management of thrombophilia and consumptive coagulopathy J Assist Reprod Genet 2011; 28:217-9.

5. Tanaka R, Fujita Y, Hiasa KI, Yumoto Y, Hidaka N, Fukushima K. Wake N. Successful management of pregnancy complicated by Klippel Trenaunay syndrome using MR angiography based evaluation. Case Rep in Obstetr and Gynaecol doi: $0.1155 / 2011 / 723467$.

6. Leon Cdo A, Braun Filho LR, Ferrari MD, Guidolin BL, Maffessoni BJ. Klippel-Trenaunay syndrome: case report. An Bras Dermatol. 2010; 85:93-6.

7. Zea MI, Hanif M, Habib M, Ansari A. Klippel-Trenaunay Syndrome: a case report with brief review of literature. J Dermatol Case Rep 2009; 3:56-9. doi: 10.3315/jdcr.2009.1038

8. Verhelst H, Van Coster R. Neuroradiologic findings in a young patient characteristic of Sturge Weber syndrome and Klippel Trenaunay Syndrome. J Child Neurol 2005; 20:91113.

9. Abdul-Rahman NR, Mohammad KF, Ibrahim S. Gigantism of the lower limb in KlippelTrenaunay syndrome: anatomy of the lateral marginal vein. Singapore Med J 2009; 50: e223-e225.

10. Chhajed M, Pandit S, Dhawan N, Jain A. Klippel- Trenaunay and Sturge- Weber overlap syndrome with phakomatosis pigmentovascularis. J Pediatr Neurosci 2010; 5:138-40. 
11. Billingham R. Klippel Trenaunay Weber syndrome- a case report. J Lymphoedema 2010; 5:99-103.
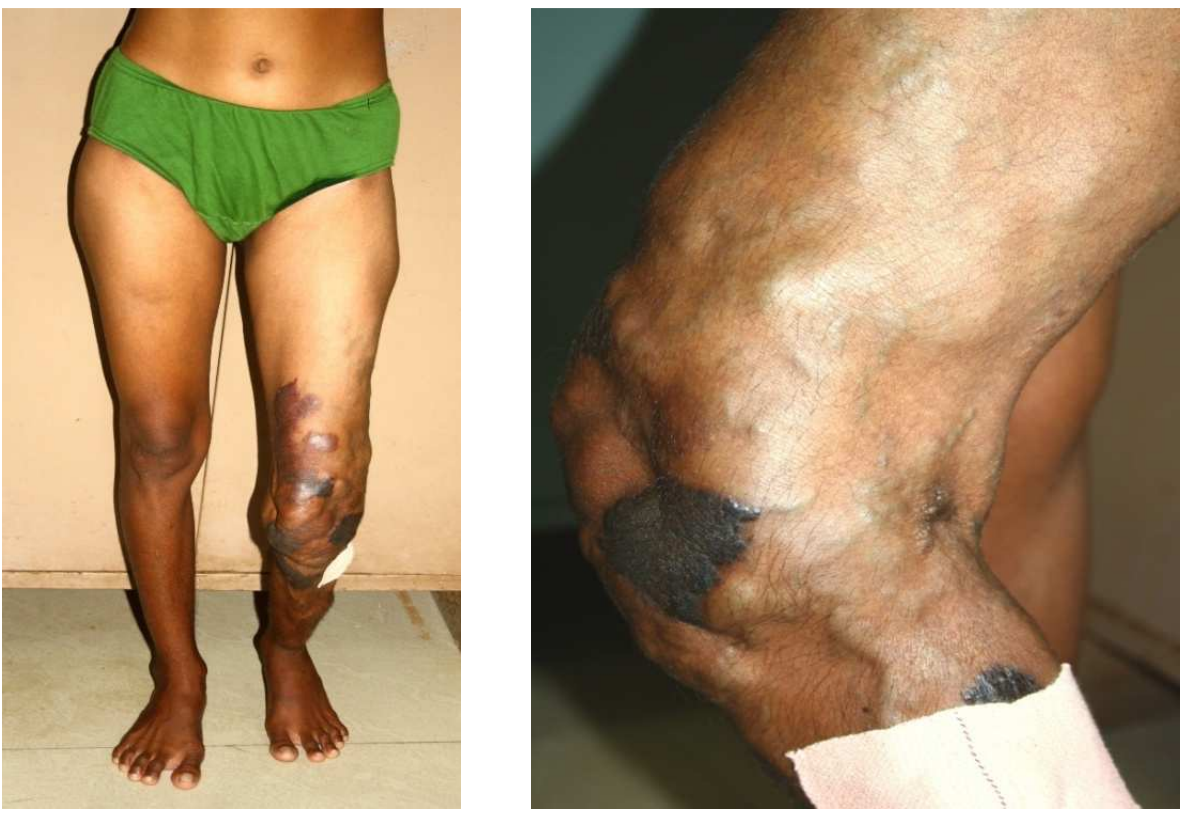

Figure 1a: Multiple, erythematous,

Figure 1b: Multiple tortuous varicosities on the limb. hyperpigmented plaques on left lower extremity with soft tissue hypertrophy.

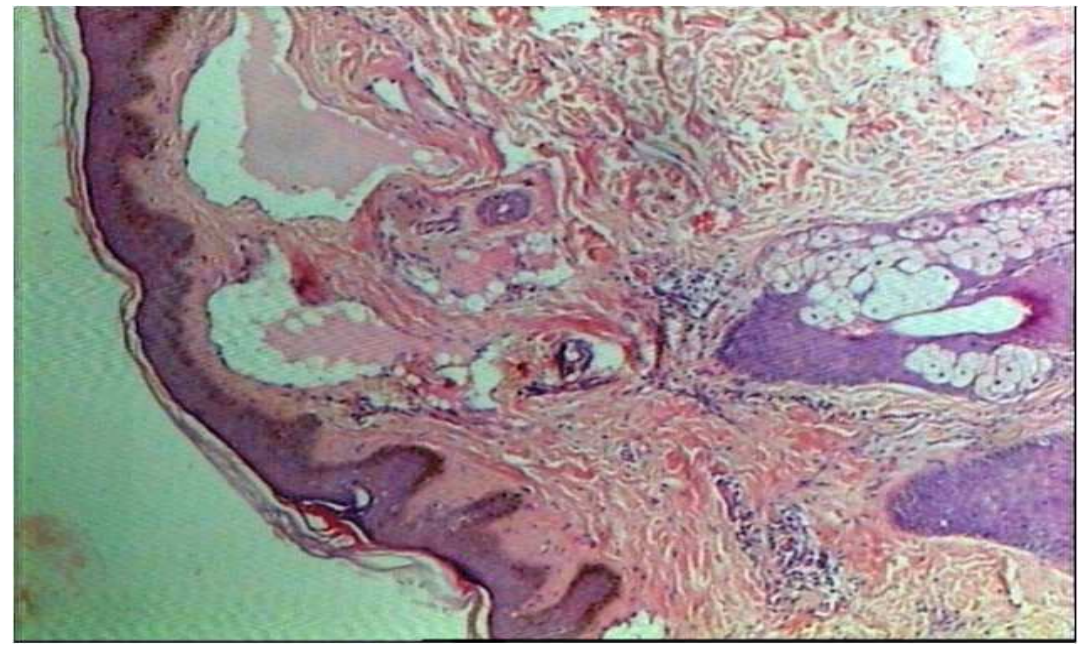

Figure 2: Nevus flammeus showing ectatic blood vessels in upper dermis with erythrocyte stasis. 